\title{
REVIEW OF REFRIGERANTS FOR STEAM COMPRESSION REFRIGERATION MACHINES
}

\author{
*Ikem, A. Ikem ${ }^{1}$, Paschal, A. Ubi ${ }^{2}$, Matthew, I. Ibeh ${ }^{3}$, Saviour, E. Ofem ${ }^{4}$, Assam, T.Assam ${ }^{5}$ \\ ${ }^{1}$ Department of Mechanical Engineering, Faculty of Engineering, \\ Cross River University of Technology, Nigeria \\ ${ }^{2}$ Department of Mechanical Engineering, Faculty of Engineering, \\ University of Calabar, Nigeria \\ ${ }^{3}$ Department of Mechanical Engineering, Faculty of Engineering, \\ Michael Okpara University of Agriculture, Umudike, Nigeria \\ ${ }^{4}$ Department of Mechanical Engineering, Faculty of Engineering, \\ Cross River University of Technology, Nigeria \\ ${ }^{5}$ Department of Mechanical Engineering, Faculty of Engineering, \\ Cross River University of Technology, Nigeria \\ E-mail: azors9kee@yahoo.com*
}

\begin{abstract}
ABSTACT:In this paper, a review is made on the effect of refrigerants on the performance of refrigerating machines. The thermodynamic, thermophysical, chemical, economic characteristics of the refrigerants and their effect on the environment especially, on the ozone layer are analysed. Various operating conditions of vapor-compression refrigerating machines (from home refrigerators to large refrigeration stations of chemical enterprises) determine a variety of refrigeration cycles and refrigerants used in them. The goal of this work is to be able to make a choice out of the many refrigerants available, appropriate machines for best application and a guide to designers for new and better machine designs. The most optimal option can be selected on the basis of thermodynamic analysis of the refrigeration cycle.
\end{abstract} KEY WORDS: Refrigerants, refrigeration, refrigeration cycle, thermodynamic characteristics, properties, ozone layer

\subsection{INTRODUCTION}

Of all the known types of refrigeration machines, the most common in the home and industry are vapor compression refrigeration machines. More than $90 \%$ of all artificial cold is produced by machines of this type. The common thing for them is that the heat flow taken from the cooled object (cooling capacity of the machine) is carried by the working body (refrigerant) boiling in a special evaporator. High energy and good weight and size parameters of steam compression refrigeration machines are largely provided by the large values of the heat of vaporization of the refrigerants used. In order for the boiling process of the refrigerant in the evaporator to be continuous, it is necessary that the agent performs a closed sequence of processes in the refrigeration machine An inverse thermodynamic cycle, which is called the refrigeration cycle for refrigeration machines. In this case, the cooling process-boiling of the refrigerant - is one of the processes of the refrigeration cycle. Various operating conditions of vapor-compression refrigerating machines (from home refrigerators to large refrigeration stations of chemical enterprises) determine a variety of refrigeration cycles and refrigerants used in them.

\section{History of Refrigerants}

A large number of substances have historically been used as refrigerating agent in vapor compression cycle of refrigerating machines. With the revolution of refrigeration technology, a number of industrially used substances have currently decreased to not more than twenty. This is has been made possible due to the development of the theory of refrigeration machines, which allows to more clearly determine the requirements for refrigerants, as well as the synthesis of special new substances for use as refrigerants. These substances are characterized by a whole set of properties, the totality of which determines the appropriateness of their use as refrigerants. These properties include:

- Thermodynamic properties on which the thermodynamic efficiency of the actual refrigeration cycle depends;

- Thermophysical properties that ensure high-efficient heat exchange in the apparatus of the refrigeration machine;

- Chemical and physicochemical properties that determine the interaction of refrigerants with the structural materials of the refrigeration machine, as well as their thermal stability; 
- Environmental and physiological properties that must meet the requirements of ecology and industrial safety; Economic properties that determine the cost to produce artificial cold. Many of the properties themselves depend on the range of temperatures and pressures at which the refrigerant is used. In this case, it is important to have a characteristic of the substance according to this property, depending on the application temperature. As a rule, there is no ideal substance that fully meets the requirements [1]. The very requirements for different properties are also sometimes in conflict with each other. Therefore, the choice of a refrigerating agent is always a compromised solution. The use of the most common modern refrigerants is historically developed. Thus, ammonia $\left(\mathrm{NH}_{3}\right)$ is widespread. It is used in machines of medium and large capacity, as a rule, to obtain medium cooling temperatures. By the end of the 19th century, ammonia had almost supplanted other refrigerants, such as ethyl chloride, sulphurous anhydride, methyl chloride and carbon dioxide. The advantages of ammonia are good thermodynamic properties, high volume cooling capacity, relatively low condensation pressure, boiling pressure close to atmospheric. At the same time, ammonia is toxic, explosive and fire - hazardous, reacts with most nonferrous metals [2]. In the thirties of the 20th century [8], refrigerants were used as freons fluorochlorobrominated derivatives of methane, ethane, propane and butane hydrocarbons. Freon is a trademark owned by the American firm DuPont, which in 1928 first synthesized Freon 12. Freons contain fluorine, chlorine and bromine in various proportions. The general chemical formula of Freonis $C_{m} H_{n} F_{p} c l_{q} B r_{r}$, where $\mathrm{m}$, $\mathrm{n}, \mathrm{p}, \mathrm{q}, \mathrm{r}$ are the numbers of atoms of the chemical elements that make up the given Freon. There are 15 types of compounds of halogen derivatives of methane, 55 - halogenated derivatives of ethane, 332 - halogenated derivatives of propane, more than 1000 - halogenated derivatives of butane. In some countries the term "freon" is used instead of the term "refrigerant". The International Organization for Standardization (ISO) introduced the international standard ISO 817-74 for the designation of refrigerants. This system consists of the name and number: the letter $\mathrm{R}$ or the word refrigerant, the numbers are related to the structure of the refrigerant molecule. In non-organic refrigerants, the figures correspond to their molecular mass, increased by 700 . For example: water $\left(\mathrm{H}_{2} \mathrm{O}\right)-\mathrm{R} 718$, ammonia $\left(\mathrm{NH}_{3}\right)-\mathrm{R} 717$, carbon dioxide $\left(\mathrm{CO}_{2}\right)-\mathrm{R} 744$. For ethane, propane and butane derivatives, compounds without hydrogen atoms are written with the digit 1 , to which is added a figure denoting the number of fluorine atoms. For example: $\mathrm{CF}_{2} \mathrm{Cl}_{2}-\mathrm{R} 12, \mathrm{CF}_{4}-\mathrm{R} 14$. For the ethane, propane and butane derivatives, 11,21,31, respectively, are placed in front of the figure that determines the number of fluorine atoms. Forexample: $\mathrm{C}_{2} \mathrm{~F}_{2} \mathrm{C}_{14}-\mathrm{R} 112, \mathrm{C}_{4} \mathrm{~F}_{7} \mathrm{C} 1-\mathrm{R} 317$. In the presence of hydrogen atoms in the methane derivatives to the first digit, and for ethane, propane and butane - to the second add a number equal to the number of unsubstituted hydrogen atoms. For example: $\mathrm{CHFC}_{12}-\mathrm{R} 21, \mathrm{C}_{2} \mathrm{H}_{3} \mathrm{~F}_{3}-\mathrm{R} 143$. In the presence of bromine atoms in a molecule of bromine, the letter $\mathrm{B}$ and a figure corresponding to the number of bromine atoms are added to the numerical designation. For example, $\mathrm{CF}_{2} \mathrm{Br}_{2}-12 \mathrm{~B} 2$.

Starting with the halogenated derivatives of ethane, there exist isomers. They have the same number and are distinguished by a lowercase letter at the end. The symmetric isomer is indicated only by numbers. The asymmetry is evidenced by lowercase letters a, b, c etc. For example: $\mathrm{CHF}_{2} \mathrm{CHF}_{2}-\mathrm{R} 134, \mathrm{CF}_{3} \mathrm{CH}_{2} \mathrm{~F}-\mathrm{R} 134 \mathrm{a}$. In the designation of non-azeotropic mixtures of refrigerants, the types of refrigerants included in the mixture and their percentages in the mixture are indicated. For example, R22/R12 (90/10) is a mixture consisting of $90 \%$ R22 and 10\% R12. In the designation, the refrigerants are arranged in order of increasing normal boiling points. Azeotropic mixtures are conventionally denoted by the numbers 500, 501, etc. If there are 10 or more fluorine atoms in the fluorine molecule, the last two digits are separated from the previous one, for example: $\mathrm{C}_{4} \mathrm{~F}_{10}-$ $\mathrm{R} 31-10$

Other refrigerants used in refrigeration machines of chemical industries include: propane $\left(\mathrm{C}_{3} \mathrm{H}_{8}\right)-\mathrm{R} 290$; Ethylene $\left(\mathrm{C}_{2} \mathrm{H}_{4}\right)-\mathrm{R} 1150$; ethane $\left(\mathrm{C}_{2} \mathrm{H}_{6}\right)-\mathrm{R} 170$ and some others [10]. When choosing these agents, the decisive role is played by the fact that these substances are the final or intermediate products of chemical technologies that use artificial cold. Refrigerants are classified according to the saturated vapor pressure and the normal boiling point. At the pressures of saturated steam, they are divided into high, medium and low pressure refrigerants. The first group includes refrigerants, in which the vapor pressure at a temperature of $+30{ }^{\circ} \mathrm{C}$ is $2-7$ $\mathrm{MPa}$. This group includes R13, R503, and R744. The pressure of the refrigerants entering the second group is 0.3-2 $\mathrm{MPa}$ (R717, R12, R22, and R134a). For refrigerants of the third group, the vapor pressure at $30{ }^{\circ} \mathrm{C}$ is lower than $0.3 \mathrm{MPa}(\mathrm{R} 11, \mathrm{R} 718$, and R113). At normal boiling points, the refrigerants are also divided into three groups: low-temperature $\left(t_{n}<-60^{\circ} \mathrm{C}\right)$, medium temperature $\left(t_{n}=60{ }^{\circ} \mathrm{C} \ldots-100^{\circ} \mathrm{C}\right)$, high-temperature $\left(t_{n}<\right.$ $\left.-10^{\circ} \mathrm{C}\right)$. Classifications by pressures and temperatures are interrelated. High-pressure refrigerants are lowtemperature working substances, low-pressure refrigerants are high-temperature [9].

\section{Thermodynamic characteristics of refrigerants}

The thermodynamic characteristics of substances used as refrigerants (Table 1) affect mainly the efficiency of thermodynamic cycles, the performance and characteristics of refrigeration machines and compressors. Thermodynamic parameters with constant values for a particular substance include the critical parametersp $\mathrm{cr}_{\mathrm{cr}}$, $\mathrm{T}_{\mathrm{cr}}, \mathrm{v}_{\mathrm{cr}}$, normal boiling point of $\mathrm{T}_{\mathrm{n}}$ (boiling point at atmospheric pressure), solidification temperature $T_{3}$, Truton constant $\mathrm{M} \cdot r_{n} / T_{n}\left(\mathrm{M}\right.$ - molar mass, $\mathrm{r}_{\mathrm{n}}$, - specific heat of vaporization at a pressure of $\left.0.1 \mathrm{MPa}\right)$, Goldberg 
number $\mathrm{T}_{\mathrm{n}} / T_{c r}$. A number of important indicators are determined by the temperature of the refrigerant and in the saturated vapor region by the pressure dependence on the temperature $p=f(t)$. This is the heat of vaporization $\mathrm{r}$; heat capacity of liquid $c^{\prime} \mathrm{x}$, dry saturated vapor $c^{\prime \prime} \mathrm{x}$, superheated steam $C_{p}, C_{v}$; entropy s and enthalpy $\mathrm{h}$. With the value of the heat of vaporization $r$, such important factors as mass specific refrigeration capacity $q_{0}$ and volume specific refrigeration capacity $q_{v}$ of the refrigeration cycle are directly related [3]. Another important thermodynamic characteristic, the adiabatic exponent $k$, is relatively independent of temperature, and it is often assumed to be a constant value when calculating refrigeration cycles [12]. The main values limiting the temperature ranges for the use of working substances are the boiling pressure $p_{0}$ and condensation $p_{k}$, and also the difference in these pressures. The pressures $p_{k}$ and $p_{0}$ in the cycle of the chiller significantly affect the design of the compressor [6]. High condensing pressure (compression end) weights the compressor design; low boiling pressures create a vacuum in the evaporator and on the suction side into the compressor, which can lead to air penetration into the system. The pressure difference $\left(p_{k}-p_{0}\right)$ determines the load on the working elements of the compressor; therefore, to reduce the mass and friction losses, it must be less.

An important characteristic of working substances is the ratio of pressures $p_{k} / p_{0}$, on the value of which the volume and energy coefficients of the compressor and the work expended depend. The ratio of the condensation and boiling pressures increases with the decrease in the normal boiling point of the substances. Usually they tend to use substances with lower $T_{n}$ values, since they are more efficient in a number of indices. However, this is not always possible, since $\left(p_{k}-p_{0}\right), p_{k} / p_{0}$ and $p_{k}$ may exceed allowed values. When comparing the values $\left(p_{k}-p_{0}\right)$, and the volumetric cooling capacity of the working substances $q_{v}$, it was found that for different refrigerants under the conditions of a given cycle $q_{v} /\left(p_{k}-p_{0}\right)=$ const.

The established regularity allows estimating the sizes of the compressor working on a little investigated working substance. At the same cooling capacity, number of cylinders, stroke and speed of rotation of the two compressors, is the equality $D_{1}^{2} \cdot q_{v 1}=D_{2}^{2} \cdot q_{v 2}$ observed where $\mathrm{D}$ is the diameter of the compressor piston cylinder. From here we get: $D_{2}=\sqrt{\frac{P_{k 1}-P_{01}}{P_{k 2}-P_{02}}}$

From this equation it follows that the lower the pressure and their difference, the larger the size of the compressor. Low-pressure working substances are not used in refrigerating machines with reciprocating compressors, since compressors will be large.

Table 1 - Properties of refrigerants

\begin{tabular}{|c|c|c|c|c|c|c|c|c|}
\hline $\begin{array}{l}\text { Working } \\
\text { substances }\end{array}$ & $\begin{array}{l}\text { Chemical } \\
\text { formula }\end{array}$ & $\begin{array}{c}\text { Molar } \\
\text { mass M, } \\
\text { kg/kmol }\end{array}$ & $\begin{array}{l}\text { Normalboi } \\
\text { ling } \\
\text { point } t_{n}{ }^{0} \mathrm{C}\end{array}$ & $\begin{array}{c}\text { Critical } \\
\text { temperature } \\
t_{\text {crit }}{ }^{0} \mathrm{C} \\
\end{array}$ & $\begin{array}{c}\text { Critical } \\
\text { Pressure } \\
P_{\text {crit }} \text { Mpa }\end{array}$ & $\begin{array}{l}\text { Specific heat of } \\
\text { vaporization at } \\
98 \mathrm{kPa} \mathrm{r}, \mathrm{kJ} / \mathrm{kg}\end{array}$ & $\begin{array}{c}\text { Gas } \\
\text { constant R, } \\
\text { J/(kg-K) }\end{array}$ & $\underset{k}{\text { Adiabaticindex }}$ \\
\hline \multicolumn{9}{|c|}{ Low pressure working substances } \\
\hline R718 & $\mathrm{H}_{2} \mathrm{O}$ & 18.016 & 100.0 & 374.15 & 22.11 & 2259.72 & 461.51 & 1.330 \\
\hline $\mathrm{R} 21$ & $\mathrm{CHFCl}_{2}$ & 102.92 & 8.73 & 178.50 & 5,173 & 239.0 & 80.78 & 1.160 \\
\hline $\mathrm{R} 123$ & $\mathrm{CP}_{3}-\mathrm{CHCl}_{3}$ & 152.9 & 27.9 & 183.8 & 3.674 & 167.6 & 54.368 & - \\
\hline R142 & $\mathrm{C}_{2} \mathrm{H}_{3} \mathrm{~F}_{2} \mathrm{Cl}$ & 100.49 & -9.20 & 136.45 & 4.138 & 223.5 & 82.74 & 1.135 \\
\hline RC318 & $C_{4} F_{8}$ & 200.04 & -5.97 & 115.32 & 2.780 & 112.0 & 41.56 & - \\
\hline \multicolumn{9}{|c|}{ Average pressure working substances } \\
\hline R12 & $\mathrm{CF}_{2} \mathrm{Cl}_{2}$ & 120.91 & -29.74 & 112.00 & 4.119 & 116.0 & 68.76 & 1.140 \\
\hline R22 & $\mathrm{CHCF}_{2} \mathrm{Cl}$ & 86.47 & -40.81 & 96.13 & 4.990 & 229.0 & 96.16 & 1.160 \\
\hline R32 & $C F_{2} F_{2}$ & 52.02 & -51.7 & 78.4 & 5.830 & 391.9 & 159.8 & - \\
\hline R125 & $\mathrm{CH} F_{2}-\mathrm{CF}_{3}$ & 120.0 & -49.3 & 66.25 & 3.631 & 161.9 & 69.275 & - \\
\hline R134a & $\mathrm{CF}_{3} \mathrm{CH}_{2} \mathrm{~F}$ & 102.03 & -26.80 & 101.10 & 4.067 & 217.8 & 81.49 & - \\
\hline R143 & $C_{2} H_{2} F_{2}$ & 84.04 & -47.58 & 73.10 & 4.110 & 226.0 & 98.93 & - \\
\hline $\mathrm{R} 152 \mathrm{a}$ & $\mathrm{CF}_{2} \mathrm{H}-\mathrm{CH}_{3}$ & 66.05 & -24.15 & 113.3 & 4.520 & 331.9 & 125.9 & - \\
\hline R290 & $\mathrm{C}_{3} \mathrm{H}_{8}$ & 44.10 & -41.97 & 96.81 & 4.269 & 419.0 & 88.55 & 1.130 \\
\hline R717 & $\mathrm{NH}_{3}$ & 17.03 & -33.35 & 132.40 & 11.397 & 1360.0 & 488.16 & 1.300 \\
\hline \multicolumn{9}{|c|}{ High pressure working substances } \\
\hline R13 & $\mathrm{CF}_{3} \mathrm{Cl}$ & 104.46 & -81.59 & 28.75 & 3.868 & 149.7 & 79.59 & - \\
\hline R14 & $\mathrm{CF}_{4}$ & 88.00 & -128.02 & -45.65 & 3.745 & 136.3 & 94.48 & 1.220 \\
\hline $\mathrm{R} 23$ & $\mathrm{CHF}_{3}$ & 70.01 & -82.14 & 26.30 & 4.811 & 239.5 & 118.76 & - \\
\hline R170 & $\mathrm{C}_{2} \mathrm{H}_{6}$ & 30.07 & -88.53 & 32.27 & 4.934 & 470.0 & 276.51 & 1.250 \\
\hline $\mathrm{R} 1150$ & $\mathrm{CH}_{2}=\mathrm{CH}_{2}$ & 28.05 & -103.74 & 9.50 & 5.056 & 465.57 & 296.37 & - \\
\hline R744 & $\mathrm{CO}_{2}$ & 44.10 & -78.50 & 31.20 & 7.383 & $573.18^{*}$ & 188.54 & 1.300 \\
\hline Air & - & 28.95 & $-192 \ldots-195$ & -140.70 & 3.756 & 196.80 & 288.0 & 1.400 \\
\hline
\end{tabular}


An important characteristic of the cycle of a refrigerating machine affecting the capacity of a compressor is adiabatic work, which decreases with increasing molar mass of the working substance [5]. This tendency is especially clearly traced for substances of the same series. The adiabatic index $\mathrm{k}$ also affects the value of the compressor operation.

From the properties of working substances (mainly from the density $\rho$ ), the hydraulic losses due to the movement of vapors in the elements of the refrigeration machine depend on the increase in the work expended. Refrigeration agents with higher vapor densities will be characterized by higher losses. To compensate for this negative effect, smaller velocities of vapor movement are taken for these agents.

Theoretical analysis of the influence of the thermodynamic characteristics of refrigerant on the energy efficiency of the refrigerating cycle of a vapor compression machine allows formulating a number of recommendations for the selection of a working substance, and confirmed by practice.

At the given temperature limits of the refrigeration cycle, the substance having the largest possible values of heat of vaporization $r$ and vapor density at the saturation line should be preferred, which provides a high volume specific cooling capacity $q_{v}$ of the cycle.

The heat capacity of the saturated liquid $c^{\prime} \mathrm{x}$ should be as small as possible, which will reduce the energy losses associated with the throttling process in the refrigeration cycle. The heat capacity of the saturated vapor $c^{\prime \prime} \mathrm{x}$ should also be minimal, and the isobaric heat capacity of the superheated steam $C_{p}$ as high as possible, which will reduce the energy losses from overheating of the steam on the compressor discharge. It should be noted that an increase in the values of heat of vaporization $r$ makes it possible to increase the value of the cooling factor $\varepsilon$ and thereby improve the performance of the refrigeration machine.

The heat capacity values $c^{\prime} \mathrm{x}, c^{\prime \prime} \mathrm{x}$ depends mainly on the nature of the processes along the lines of saturated liquid and saturated steam. The steeper the lines representing these processes in the T-s diagram, the smaller the value of $c^{\prime} \mathrm{x}, c^{\prime \prime} \mathrm{x}$. It follows from this that as the temperature boundaries of the cycle (and primarily $T_{k}$ ) approaches $T_{c r}$, the energy losses associated with both throttling and overheating increase. Therefore, when choosing a substance as a refrigerant, they tend to ensure that $T_{k} / T_{c r}$ do not exceed 0.85 .

The nature of the thermodynamic cycle losses depends on the properties of the working substances and varies for different refrigerants [4]. Depending on the nature of the loss of each working substance, the cycle of the refrigerating machine must consist of different processes. For substances that have large values of $c^{\prime} \mathrm{x}$ and small values of $c^{\prime \prime} \mathrm{x}$ (e.g., R12, R22), you must include processes that reduce losses from throttling, and vice versa, for compounds with small values of $c^{\prime} x$ (e.g., R717), processes that reduce losses from superheating of steam during compression are preferred.

It is impossible to find a substance that would ideally meet all of the above requirements. The most optimal option can be selected on the basis of thermodynamic analysis of the refrigeration cycle. In this case it is necessary to take into account, in addition to thermodynamic ones, other properties of the substance.

\section{Thermophysical properties of refrigerants}

Thermophysical [11] properties of refrigeration agents include density $\rho$, thermal conductivity $\lambda$, thermal diffusivity a, kinematic viscosity $v$, dynamic viscosity $\mu$, surface tension $\sigma$, and some other properties. They affect the intensity of heat and mass transfer in the chiller machines, as well as the hydraulic resistance during the movement of gaseous and liquid refrigerants in the system. These factors determine the values of irreversible losses in the processes of heat and mass transfer and transportation of working substances, which ultimately affects the overall energy efficiency of refrigeration machines and their design features. For heat and mass transfer in devices with a relatively high intensity, it is desirable to have refrigerants with large values of thermal conductivity, density, heat of vaporization, and low viscosity values.

The resistance to the circulation of working substances in the system is affected by viscosity and density. The mass flow rate of the refrigerant circulating in the system depends on the heat of vaporization and decreases with its growth. In order to reduce the energy consumption for pumping refrigerant in the system, it is desirable to have as large a value of heat of vaporization and the lowest values of viscosity. As a general characteristic of the properties of working substances for heat transfer during boiling and condensation, the critical parameters of the working substances and their molar mass can be chosen. The heat transfer during boiling and condensation increases with other conditions equal to the decrease in $T_{c r}$ and the molar mass $\mathrm{M}$ and decreases with increasing $p_{k p}$ at boiling and with a decrease in $p_{c r}$ at condensation.

\section{Chemical and physicochemical properties of refrigerants}

The chemical stability of refrigerants is characterized by decomposition temperature, flammability and explosiveness [7]. The decomposition temperatures of the agents used in the vapor compression machines are much higher than the temperatures at which the thermodynamic cycles are carried out. In using refrigerants in regenerative cycles, the temperature of the compression end don't exceed $70-100{ }^{\circ} \mathrm{C}$, when using ammonia - 150 ${ }^{0} \mathrm{C}$. 
The thermal stability of refrigerants differs [13]. Ammonia begins to disintegrate into nitrogen and hydrogen at a temperature above $250{ }^{\circ} \mathrm{C}$, carbon dioxide at a temperature above $1500{ }^{\circ} \mathrm{C}$. The thermal stability of refrigerants is quite high, but the decomposition of these compounds is accompanied by the formation of hydrogen chloride and fluoride, as well as traces of phosgene. The initial temperature of the decomposition of refrigerants increases with increasing fluorine content in the molecule and depends on the materials in contact with which they are located. It is higher when in contact with nickel and high-alloy steels and decreases in the presence of carbon steels. The R12 refrigerant in the presence of iron, zinc, duraluminum, copper begins to decompose at $410-430{ }^{\circ} \mathrm{C}$, in the presence of lead at $330{ }^{\circ} \mathrm{C}$, refrigerant R22 in the presence of iron at $550{ }^{\circ} \mathrm{C}$. Based on the analysis of the published data [14], it can be concluded that the relative thermal stability of the refrigerants decreases in the following order: R11 $<\mathrm{R} 21<\mathrm{R} 113<\mathrm{R} 22<\mathrm{R} 12<\mathrm{R} 114<\mathrm{R} 115<\mathrm{R} 318 \mathrm{C}<\mathrm{R} 13<\mathrm{R} 14$. Refrigerants R14, R318C, R218 are thermally very stable; they decompose only at the temperature of red heat. The least resistant to the influence of high temperatures is brominated hydrocarbons.

The thermal stability of refrigerants is reduced in the presence of lubricating oils. Mineral oils have a greater effect on the deterioration of thermal stability than synthetic oils [15]. Decomposition of agents has a negative effect on the reliability of compressors and the duration of use of lubricating oils in them without replacement. The solubility of the refrigerating agent and impurities, which primarily include water and lubricating oil, has a significant influence on the design of the refrigerating machine and the refrigeration cycle.

When operating refrigerating machines, it is extremely important to ensure that there are no water, noncondensable gases and other impurities in the refrigerants. The impurities contained in the refrigerant affect its thermodynamic properties, especially at low pressures, increasing the temperature and boiling pressure. The limits of moisture and other impurities in the refrigerants are set by the State standards. Ammonia and water have full mutual solubility. Technical ammonia should contain no more than $0.2 \%$ water. The solubility of water in liquid refrigerants is small and is at a temperature of $15.6^{\circ} \mathrm{C}$ depending on the type of refrigerant $0.01-$ $0.10 \%$ (by weight). The presence of undissolved moisture in the refrigerant leads to the risk of ice formation in the throttling devices of the refrigerating machine. Already a small amount of moisture causes hydrolysis of refrigerants with the formation of hydrochloric and hydrofluoric acids. The resulting acids have a corrosive effect on the metal parts of refrigeration machines and destroy the electrical insulation of built-in electric motors. The most frequently affected elements by corrosion of the refrigeration machine are the compressor, the throttle body and the evaporator. Pure hydrocarbons (ethane, propane, isobutane) do not react with water. Freon R12 for sealed machines must contain no more than $0.0004 \%$ (by weight) of moisture, Freon R12 - no more than $0.0025 \%$ (by weight). To ensure a safe level of humidity in the refrigeration machine system, dehumidifier filters are installed. As adsorbents, silica gel, active alumina, $\mathrm{NaA}$ and $\mathrm{NaAm}$ zeolites are used.

Lubricating oils are used in refrigeration compressors to create an oil film between the friction parts, reducing friction and wear; they also cool the parts and seal the gaps. The oil in the machine must meet the requirements of viscosity, oil content and stability at different temperatures and pressures.

The operating conditions of refrigeration machines dictate to oils the following requirements: at low temperatures, solid paraffin particles should not drop out of the oil, and it should remain sufficiently fluid, at high temperatures coking and formation of asphalts and resins should not occur, the oil should be stable for many years of operation. The viscosity of the oils used at $50{ }^{\circ} \mathrm{C}$ should be at least $16 \mathrm{~mm}^{2} / \mathrm{s}$. The pour point of the oils should be below their operating temperatures. For the operation of oils in refrigeration machines, the socalled cloud point, at which heavy hydrocarbons (paraffins) drop out of the oils, is of great importance [15]. Precipitation of paraffins in evaporators, in narrow sections of the throttling organs, disrupts the operation of the chiller. Therefore, the cloud point must in all cases be below the boiling point of the refrigerant in the evaporator. Lubricating oils must be thoroughly drained. The water content of the oil should not exceed 20 parts per million parts of oil. Dehydrated oil is very hygroscopic, it absorbs up to $1 \%$ of water, so it should be contained in a sealed container and possibly less contact with outside air.

Working substances react differently with oils. Ammonia does not dissolve oil, and therefore, in ammonia refrigerating machines, separating the oil after the compressor in the oil separators minimizes the possibility of getting it into heat exchangers. The effect of dissolved oil in the coolant affects both the thermodynamic and thermophysical properties of the working substance, and on conditions of heat transfer and hydraulic resistance. The presence in the coolant of the dissolved oil impairs the heat transfer upon condensation and boiling of this refrigerant.

In terms of the degree of mutual solubility with mineral oils, the working substances can be divided into three groups: with limited solubility, with unlimited solubility; with limited solubility in a certain temperature range (intermediate). Substances of the first group in the saturated state dissolve in oil in a small amount. With increasing amount of oil, the mixture is divided into two layers - oil and refrigerant. With a greater density of the refrigerant, the oil layer floats up, and at a lower level it settles. Substances of the second group in the supercooled state with oil mutually dissolve in unlimited quantities. In the state of saturation, the amount of working substance that dissolves in the oil depends on the temperature of the solution and the vapor pressure 
above it: with increasing pressure and a decrease in temperature, the concentration of refrigerant in the oil increases.

At constant pressure, a decrease in temperature causes absorption, while a rise in temperature causes sublimation of the coolant. Substances of the third group dissolve in oil unlimitedly at high temperatures. Below a certain critical dissolution temperature, the solution is divided into two layers. It is necessary to choose the oil with the lowest possible critical dissolution temperature: $\mathrm{R} 22$ has a critical dissolution temperature $T_{p} . k_{p}=$ $24^{\circ} \mathrm{C}$, so it unlimitedly dissolves in the oil at high temperatures (in the condenser), and at low temperatures (in the evaporator) it will separate; R12 has $T_{p} . k_{p}=-45^{\circ} \mathrm{C}$, therefore in the working processes of the refrigerating machine occurring at temperatures above this value, such a refrigerant has unlimited solubility.

As the solubility of the liquid working substance increases, so does the solubility of its vapor in the oil. The concentration of oil in the vapor is insignificant, however, the partial pressure of the refrigerant vapor in the mixture has a lower value than the pure substance, and therefore the boiling point of the liquid dissolved in the oil at the same pressure will be higher than the temperature of the pure substance.

The solubility of refrigerants with increasing fluorine atoms in the compound decreases. The substances R13, $\mathrm{R} 14, \mathrm{R} 115, \mathrm{R} 22$, and R114 practically do not dissolve in mineral oils and the azeotropic mixture of R152 and R12 dissolves partially; R11, R12, R21, R113 dissolve without limit. Fluorinated hydrocarbons C3F8, C4F10 etc. possess low solubility [16].

In the working substances of the second group, when using heavy oils and at low temperatures, a zone of incompressibility is detected. Substances of the third group (R22) pass into the second when using light or synthetic oils.

In the case where the working substance is not soluble in oil, there is no foam in the evaporator by boiling, which contributes to a more stable operation of the refrigerating machine. The solubility of the working substance in the oil contributes to the fact that the oil layer is almost completely washed off the heat transfer surfaces, and in the evaporators of the non-flooded systems it is carried away together with the liquid. The use of refrigerants that dissolve well in oils (e.g. R12) necessitates the installation of recuperative heat exchangers. In the heat exchanger there is not just overheating of pure steam, but, mainly, the evaporation of the working substance from the solution with an increasing steam temperature.

An important chemical property of the refrigerant is its interaction with structural materials [17]. Refrigerants and their solutions with lubricating oils should be chemically inert to metals and their alloys and other structural materials, if possible. Ammonia does not corrode steel, but in the presence of moisture reacts with zinc, copper, bronze and other alloys containing copper. Carbon dioxide, propane, isobutene are inert to all metals. In the dehydrated state, the refrigerants are inert to all metals at temperatures within which the thermodynamic cycles of the refrigerating machines are carried out. Exceptions are alloys containing more than $2 \%$ magnesium. All fully fluorinated organic compounds are chemically neutral.

Refrigerants are good solvents; therefore many nonmetallic materials in them are unstable. Interaction of refrigerants with such structural materials leads to their swelling, diffusion of refrigerants and, as a result, loss of tightness of the system. The most vulnerable on the part of refrigerants are non-metallic electrical insulation, gasket-sealing and other materials. This effect is further enhanced by the fact that the maximum heating temperatures in the insulation system in modern machines reach $140-180{ }^{\circ} \mathrm{C}$. Non-metallic structural materials used in cold storage chillers must have a high density to avoid leakage of refrigerants through the pores. For gaskets in refrigerant machines, it is recommended to use paronite, fluoroplastic, special (nephrite) rubber, and as binders and insulating varnishes - polyvinyl acetates and polyamides.

\section{Environmental and physiological properties of refrigerants}

Individual refrigerants (mainly freons) are a source of destruction of the ozone layer of the earth's atmosphere. A number of agents in the atmosphere create a greenhouse effect, and more than $95 \%$ of the world production of freons accounts for substances such as R11, R12, R22, R113, R115, etc.

The chemical stability of CFCs is so high (table 2) that the molecules of these substances do not break down in the troposphere (the lower part of the atmosphere up to $16 \mathrm{~km}$ high) and reach the stratosphere (the atmosphere layer from 16 to $45 \mathrm{~km}$ ). Under the action of ultraviolet radiation, the molecules of freons disintegrate with the liberation of chlorine atoms, which react with ozone to form oxides and oxygen.

For refrigeration, the main challenge is to drastically reduce the use of the most common ozone-active refrigerant, R12 [18]. Part of this reduction can be offset by increased use of the most versatile and one of the most common R22 refrigerants with low ozone activity. It is practically possible and expedient to switch to R22 when creating new refrigerating machines and compressors operating at a condensation temperature up to $55^{\circ} \mathrm{C}$ and a boiling point up to minus $70{ }^{\circ} \mathrm{C}$. 
Table 2- Potentials of the ozone-depleting and greenhouse effect of widely usedrefrigerants

\begin{tabular}{|c|c|c|c|}
\hline \multicolumn{2}{|c|}{ Refrigerant } & $\begin{array}{c}\text { Ozone-depleting } \\
\text { potential }\end{array}$ & $\begin{array}{c}\text { Greenhouse effect } \\
\text { potential }\end{array}$ \\
\hline Symbol & Chemical formula & 1.0 & 1.0 \\
R12 & $\mathrm{CFCl}_{3}$ & 1.0 & 3.0 \\
$\mathrm{R} 22$ & $\mathrm{CF}_{2} \mathrm{Cl}_{2}$ & 0.05 & 0.36 \\
R113 & $\mathrm{CHFCl}_{2}$ & 0.8 & - \\
R114 & $\mathrm{C}_{2} \mathrm{~F}_{3} \mathrm{Cl}_{3}$ & 1.0 & 3.9 \\
R115 & $\mathrm{C}_{2} \mathrm{~F}_{4} \mathrm{Cl}_{2}$ & 0.6 & 7.5 \\
R12B1 & $\mathrm{C}_{2} \mathrm{~F}_{5} \mathrm{Cl}$ & 3.0 & - \\
R13B1 & $\mathrm{CF}_{2} \mathrm{BrCl}$ & 10.0 & - \\
\hline
\end{tabular}

Another important area is the development and organization of industrial production of new alternative ozonesafe refrigerants (table 3).

According to expert estimates, the greatest preference is given to refrigerants R22, ammonia, R134a, R123a, hydrocarbons,R22/R142a, R22/R152a, R226, and R227. For refrigeration equipment R134a is proposed instead of R12 along with R22. A number of foreign companies have mastered the production of domestic refrigeration units with the latest refrigerant [19].

Table 3 - characteristics of alternative ozone-safe refrigerants

\begin{tabular}{|c|c|c|c|}
\hline $\begin{array}{l}\text { Commonly used } \\
\text { refrigerant }\end{array}$ & Boiling point, ${ }^{0} \mathrm{C}$ & Alternative refrigerant & Boiling point, ${ }^{0} \mathrm{C}$ \\
\hline R113 & 46.8 & $\mathrm{R} 132 \mathrm{~b}$ & 46.8 \\
\hline $\mathrm{R} 11$ & 23.6 & $\mathrm{R} 123 / 123 \mathrm{a}$ & 27.1 \\
\hline R114 & 3.6 & R133a; R21 & $6.1,9.0$ \\
\hline $\mathrm{R} 12 \mathrm{~B} 1$ & -3.8 & $\mathrm{R} 142 \mathrm{~b}$ & -9.0 \\
\hline $\mathrm{R} 142 \mathrm{~b}$ & -9.0 & $\begin{array}{c}\text { R142B } \\
\text { R134a; R152a; R22/R142B }\end{array}$ & $\begin{array}{c}-9.0 \\
-26.8,-24.7,-30.0\end{array}$ \\
\hline $\mathrm{R} 12$ & -29.8 & $\mathrm{R} 22 / \mathrm{R} 142 \mathrm{~b}$ & \\
\hline R500 & -33.3 & & -33.0 \\
\hline R22 & -40.8 & $\begin{array}{l}\text { R22/R134a; R22; R125 } \\
\text { R502; R143b }\end{array}$ & $-33.0,-40.8,-42.0$ \\
\hline R502 & -45.6 & $\mathrm{R} 32$ & $-45.6,-47.6$ \\
\hline R13B1 & 57.0 & R13; R23; R503 & -51.7 \\
\hline $\mathrm{R} 13$ & 81.6 & & $-81.6,-82.0,-87.8$ \\
\hline R14 & -128.0 & R14 & -125.0 \\
\hline
\end{tabular}

The pressure values of R134a are close to the pressure values of R12. Studies show that from industrial safety stand point, R134a is similar to R12 and R22, but longer experiments are needed to make this conclusion final. Low molar mass and high latent heat of vaporization, as well as high thermal conductivity create certain advantages of R134a use in the refrigeration cycle. At the same time, the higher specific heat of the refrigerant in question is not in favor of the first. R134a refrigerant is thermally more resistant than R12, but its significant drawback is the low solubility in the traditionally used refrigeration oils. For this refrigerant, a special synthetic (polyester) oil HS-22 is created. It has a high hygroscopicity, which puts forward very strict requirements for cleaning and drying the system of the refrigeration unit, drying oil before refilling.

A comparison of the efficiency of refrigeration machine cycles on R134a and R12 shows that theoretically the efficiency of the cycle on R134a is $96-98 \%$ of the efficiency of the cycle at R12. At equal boiling and condensation temperatures in the cycle for R134a compared to the cycle for R12 of the pressure in the evaporator and the condenser is lower, the ratio of the condensation and boiling pressures is higher, although the difference in these pressures is lower. With the same regeneration, the specific volume cooling capacity of the cycle on R134a is lower by $8-12 \%$, and the thermal tension of the compressor is slightly higher. Since the molar mass of R134a is smaller, the hydraulic losses in the piston compressor valves will be lower compared to R12.

Along with R134a, other ozone-friendly refrigerants are also considered for household refrigerators. Part of the available proposals provides for the removal of the requirement of the non-combustibility of the working substance. At the same time, explosion and fire safety are caused by a small amount of charged refrigerant and are provided with some design changes. It is primarily about saturated hydrocarbons. A completely equivalent substitute for R12 is the azeotropic mixture R152a/R600a (0.8/0.2), belonging to the group of combustible 
substances. The specific volumetric cooling capacity of this mixture is $5 \%$ lower than that of the refrigerant $\mathrm{R} 12$, the refrigerating coefficient of the cycle is the same as the cycle for R12. The energy consumption of household refrigerators with this mixture is on average $10 \%$ less than with R12. To replace R12 and R502 in the existing refrigeration equipment, "DuPont de Nemours" offers refrigerant mixtures that include R22, R152a, R124, R125, and R290. They are quasi-septic.

Nevertheless, a large number of previously released refrigeration equipment and to this day continues to work on the refrigerant $\mathrm{R} 12$, which determines its production and sale.

Of the alternative refrigerants to date, ammonia, R22, R23, R32 and R152a are produced commercially (primarily for azeotropic mixtures R503 and R500).

According to the degree of toxicity of refrigerants, refrigerators are divided into six classes. The classification is based on an experimental study of the physiological effects of refrigerant vapors on experimental animals. The maximum permissible concentration (MPC) of most refrigerants has been determined (Table 4). At the same time, the MPC does not fully reflect the real danger of working with refrigerants in production conditions. Thus, for R11 and R12B1, the MPCs are equal and amount to $1000 \mathrm{mg} / \mathrm{m}^{3}$. However, at $20{ }^{0} \mathrm{C}$, the saturated vapor pressure of $\mathrm{R} 12 \mathrm{~B} 1$ is $0.23 \mathrm{MPa}$, and $\mathrm{R} 11$ is only $0.09 \mathrm{MPa}$, and the saturated vapor density of R12B1 is, respectively, more than three times that of R11. This means that when the system is depressurized, the refrigerant R12B1 enters the air of the working area faster and in a larger amount than R11.

The real danger of poisoning with a refrigerant is recommended to estimate the toxic hazard coefficient $K_{t 0}$, which is a dimensionless value obtained by the ratio of the vapor density $\rho_{20}$ at $20{ }^{0} \mathrm{C}$ to the MPC set for the air of the working zone: $K_{t 0}=\rho_{20} / M P C$. The toxic hazard ratio shows how many times the maximum permissible exposure limit can be exceeded in an emergency in a real-world production environment. With the increase of $K_{t 0}$ more precautions should be taken when working.

Table 4-MPC Values of some refrigerants

\begin{tabular}{|c|c|c|c|c|c|c|c|c|}
\hline Refrigerant & $\begin{array}{c}\text { MPC, } \\
m g / m^{3}\end{array}$ & $\begin{array}{c}K_{t 0} \\
.10^{-3} \\
\end{array}$ & Refrigerant & $\begin{array}{c}\text { MPC, } \\
m g / m^{3}\end{array}$ & $\begin{array}{c}K_{t 0} \\
.10^{-3} \\
\end{array}$ & Refrigerant & $\begin{array}{c}\text { MPC, } \\
m g / m^{3}\end{array}$ & $\begin{array}{c}K_{t 0} \\
.10^{-3} \\
\end{array}$ \\
\hline R10 & 20 & 40 & $\mathrm{R} 21$ & 200 & 30 & $\mathrm{R} 150$ & 10 & 50 \\
\hline R11 & 1000 & 5 & R22 & 3000 & 10 & $\mathrm{R} 152$ & 3000 & 1 \\
\hline R12 & 300 & 100 & $\mathrm{R} 30$ & 50 & 30 & RC318 & 3000 & 7 \\
\hline R12B1 & 1000 & 20 & R32 & 1 & 3200 & RU50 & 50 & 20 \\
\hline R12B2 & 860 & 9 & $\mathrm{R} 40$ & 5 & 2000 & R500 & 3000 & 9 \\
\hline $\mathrm{R} 20$ & 20 & 60 & R40B1 & 1 & 5000 & R502 & 3000 & 20 \\
\hline R20B3 & 5 & 40 & R113 & 3000 & 1 & R717 & 20 & 300 \\
\hline $\mathrm{R} 114$ & 3000 & 4 & $\mathrm{R} 115$ & 3000 & 20 & $\mathrm{R} 130 \mathrm{a}$ & 5 & 40 \\
\hline R114B2 & 1000 & 4 & & & & & & \\
\hline R143 & 3000 & 90 & R130 & 5 & 30 & R142 & 3000 & 4 \\
\hline
\end{tabular}

Ammonia (R717) has a sharp characteristic smell and irritates the mucous membranes of the eyes, stomach, and respiratory tract, cause spasms of the respiratory organs, and skin burns. Its presence in the air is felt already at a volume concentration of $0.0005 \%$. Prolonged stay in the zone with ammonia content in the air over $0.5 \%$ by volume leads to poisoning. For refrigerants R11, R21 the lethal concentration is $10 \%$ (by volume), for R12 and R22 - 20\% (by volume). Fully fluorinated refrigerants are among the least toxic compounds. Practically R12B1, R13B1, R114B2 are non-toxic.

Refrigerants have varying degrees of flammability and explosiveness. Ammonia in contact with air at concentrations of $16-26.8 \%$ is explosive and flammable. The greatest explosive properties are ethane, ethylene, propane and butane. So, from the point of view of flammability, the permissible norm of ethane and propane in air should not exceed $40 \mathrm{~g} / \mathrm{m}^{3}$, ethylene $-32 \mathrm{~g} / \mathrm{m}^{3}$. The explosiveness and flammability of refrigerants are markedly reduced with a decrease in the number of hydrogen atoms in the molecule and an increase in the number of atoms of chlorine, fluorine and, especially, bromine. Carbon dioxide, R22, R23, R123, R124, R125, R134, R134a are not flammable or explosive.

\section{Conclusion and Recommendations}

A large number of substances have been historically used as refrigerating agent in vapor compression cycle of refrigerating machines which has been made possible due to the development of the theory of refrigeration machines, which clearly determines the requirements for refrigerants. The thermodynamic characteristics of refrigerants affect mainly the efficiency of thermodynamic cycles, the performance and characteristics of refrigeration machines and compressors. They have varying degrees of flammability and explosiveness. Their thermophysical properties include density, thermal conductivity, thermal diffusivity, kinematic viscosity, dynamic viscosity, surface tension, and some other properties. Their chemical stability is characterized by 
decomposition temperature, flammability and explosiveness. Individual refrigerants (mainly freons) are a source of destruction of the ozone layer of the earth's atmosphere. Good choices of refrigerants and machines should be made to save our planet.

\section{REFERENCES}

[1] А.В.Бараненко, Н.Н.Бухарин, В.И.Пекарев, И.А. Сакун, Л.С. Тимофеевский; Refrigeratingmachines: Техtbook; underthegeneraleditorshipofЛ.С. Тимофеевского- St. Petersburg: Polytechnic, - pp.992. 1997.

[2] ANSI/ASHRAEStandard 97-2007

[3] Calm, J. and D. Didion, 1998, “Trade-offs in refrigerant selections: past, present, and future”, lnt. J. Refrig. Vol. 21, No. 4, pp. 308321.

[4] Cavallini, A., C. Zilio, J.S. Brown, 2010, "Sustainability with prospective refrigerants", Proc. IIR/EurothermSustainable Refrigeration and Heat Pump Technology Conference, Stockholm, Sweden.

[5] Clodic, D.,2010, "Low GWP refrigerants and flammability classification", 2010 International Symposium on Next-generation Air Conditioning and Refrigeration Technology, 17 - 19 February 2010, Tokyo, Japan

[6] СоколовЕ.Я., БродянскийВ.M. Energy bases of heat transformation and cooling processes: Studies. Manual-Moscow: Energy output, - p.320, 1981.

[7] Huttenlocher, D. F., "Chemical and Thermal Stability of Refrigerant/Lubricant Mixtures with Metals" (1992). International Refrigeration and Air Conditioning Conference. Paper 209.http://docs.lib.purdue.edu/iracc/209

[8] Huttenlocher, D.F. 1992. Chemical and thermal stability of refrigerant-lubricant mixtures with metals.Final Report DOE/CE $23810-5$. ARTI refrigerant database. Air-Conditioning, Heating, and Refrigeration Institute, Arlington, VA.

[9] IPCC. 2013. Climate Change 2013: The Physical Science Basis. Contribution of Working Group I to the Fifth Assessment Report of the Intergovernmental Panel on Climate Change. Cambridge University Press, Cambridge, United Kingdom and New York, NY, USA.

[10] Kondo S., K. Takizawa, A. Takahashi, K. Tokuhashi, J. Mizukado, A. Sekiya, 2009, "Flammability limits of olefinic and saturated fluoro-compounds", J. Hazardous Materials, Vol. 171, pp. 613 - 618.

[11] McLinden, M., 1987, "Thermodynamic evaluation of refrigerants in the vapour compression cycle using reduced properties", Int. J. Refrig., Vol. 11,pp. $134-143$.

[12] РозенфельдЛ.М., ТкачёвА.Г. Refrigeration machines and apparatuses. - Moscow: Gostorg publishers, - p.656, 1960.

[13] Yamada, Y., T. Tsuchiya and T. Shibanuma, 2010, Environmentally friendly non-flammable refrigerants, 2010 International Symposium on Next-generation Air Conditioning and Refrigeration Technology, 17 - 19 February 2010, Tokyo, Japan

\section{Nomenclature}

\begin{tabular}{|clll|}
\hline MPC & Maximum Permissible Concentration $\left(\mathrm{mg} / \mathrm{m}^{3}\right)$ & $\mathrm{r}$ & Heat of vaporization $(\mathrm{J} / \mathrm{g}$ or J/mol.) \\
$p_{0}$ & Boiling pressure (MPa) & $\mathrm{s}$ & Entropy $(\mathrm{kJ} / \mathrm{kg})$ \\
$p_{k}$ & Condensation pressure (MPa) & $\rho$ & Density $\left(\mathrm{g} / \mathrm{m}^{3}\right)$ \\
$q_{v}$ & Volume specific refrigeration capacity $(\mathrm{kJ} / \mathrm{kg} \mathrm{K})$ & $\mathrm{h}$ & Enthalpy $(\mathrm{kJ} / \mathrm{kg})$ \\
$q_{0}$ & Mass specific refrigeration capacity $(\mathrm{kJ} / \mathrm{kg} \mathrm{K})$ & $\mathrm{k}$ & Adiabatic index $(-)$ \\
$r_{n}$ & Specific heat of vaporization $(\mathrm{J} / \mathrm{kg})$ & $t_{n}$ & Normal boiling temperature $\left({ }^{0} \mathrm{C}\right)$ \\
$T_{k}$ & Throttling temperature $\left({ }^{0} \mathrm{C}\right)$ & $c^{\prime} \times$ & Heat capacity of liquid $(\mathrm{kJ} / \mathrm{kg})$ \\
$C_{p}$ & Specific heat at constant pressure $(\mathrm{J} / \mathrm{kg})$ & $c^{\prime \prime} \times$ & Specific heat of dry saturated vapor $(\mathrm{kJ} / \mathrm{kg})$ \\
$C_{v}$ & Specific heat at constant volume $(\mathrm{J} / \mathrm{kg})$ & $\mathrm{v}_{\mathrm{cr}}$ & Critical volume $\left(\mathrm{m}^{3}\right)$ \\
$T_{c r}$ & Critical temperature $\left({ }^{0} \mathrm{C}\right)$ & $\mathrm{M}$ & Molar Mass $(\mathrm{mol})$. \\
$\mathrm{ISO}$ & International Standard Organization & & \\
\hline
\end{tabular}

